\section{Neurotoxicity related exposure to ambient nanoparticles}

\author{
Mojtaba Ehsanifar ${ }^{1,2 *}$, Zeinab Montazeri ${ }^{3}$ and Mehravar Rafati ${ }^{4}$
}

1'Department of Environmental Health Engineering, School of Public Health Iran University of Medical Sciences, Tehran, Iran

${ }^{2}$ Anatomical Sciences Research Center, Kashan University of Medical Sciences, Kashan, Iran ${ }^{3}$ Institute of Endocrinology and Metabolism Research and Training Center, Iran University of Medical Sciences, Tehran, Iran

${ }^{4}$ Department of Medical Physics and Radiology, Faculty of Paramedicine, Kashan University of Medical Sciences, Kashan, Iran

\section{Abstract}

Air pollution exposure is among the most prevalent reasons for environmentally-induced oxidative stress and inflammation, both of which are implicated in the central nervous system (CNS) diseases. The CNS has emerged as an important target for adverse health effects of exposure to air pollutants, where it can cause neurological and neurodevelopmental disorders. Air pollution includes various components of gases, particulate matter (PM), ultrafine particulate (UFPs), metals, and organic compounds. An important source of PM and UFPM in the ambient air is associated with air pollution-related trafficking, and primarily diesel exhaust particles (DEPs). Controlled animal studies and epidemiological studies show that exposure to air pollution, and in particular urban air pollution or DEPs, may lead to neurotoxicity. In specific, exposure to air pollutants as an important factor may be in neurodevelopmental disorders (eg Autism) and neurological disorders (eg.., Alzheimer's Disease (AD)). The most noticeable effects of exposure to air pollutants in animals and humans are oxidative stress and neurodegeneration. Studies in rats exposed to DEPs showed microglial activity, increased lipid peroxidation, and neuronal accumulation in various areas of the brain, especially the olfactory bulb (OB) and the hippocampus (HI). Disorders of adult neurogenesis were also found. In most cases, the effects of DEP are more pronounced in male mice, probably due to lower antioxidant capacity due to less expression of paraoxonase 2 .

\section{More Information}

*Address for Correspondence: Mojtaba Ehsanifar, Department of environmental health engineering, School of public health Iran University of medical sciences, Tehran, Iran, Email: ehsanifar@gmail.com

Submitted: December 20, 2021

Approved: January 17, 2022

Published: January 18, 2022

How to cite this article: Ehsanifar M, Montazeri Z, Rafati M. Neurotoxicity related exposure to ambient nanoparticles. J Neurosci Neurol Disord. 2022; 6: 005-010.

DOI: 10.29328/journal.jnnd.1001060

ORCiD: orcid.org/0000-0003-1005-2501

Copyright License: () 2022 Ehsanifar M, et al This is an open access article distributed under the Creative Commons Attribution License, which permits unrestricted use, distribution, and reproduction in any medium, provided the original work is properly cited.

Keywords: Air pollution exposure; Diesel exhaust particles; Neurotoxicity; Oxidative stress; Neuro-inflammation; CNS diseases; Neurodevelopmental disorders

Check for updates

OPEN ACCESS

\section{Introduction}

Air pollution is a combination of various components, including gases, particulate matter (PM), metals, organic compounds, and the second factor is believed to be the most widespread health threat [1]. In many countries, especially South and East Asia, the population is often exposed to large amounts of PM $\left(\geq 100 \mu \mathrm{g} / \mathrm{m}^{3}\right)$ [2]. PM is usually characterized by aerodynamic diameter: for example, PM10 is made up of particles with a diameter of 10 microns, while PM2.5 shows particles with diameters of less than 2.5 microns. It is also of paramount importance for PM (diameter UFPs < $100 \mathrm{~nm}$ ) which can easily reach the general circulation and be distributed to various organs including the brain [3]. The UFPM can also through the nasal olfactory mucosa and reach first the olfactory bulb access the brain [4,5]. Diesel exhaust (DE) is the most important component in urban air pollution [6,7]. DE contains more than 40 toxic air pollutants, most notably fine particles (PM2.5) and ultra-fine particles
$[8,9]$. Diesel engines provide power for a wide range of heavy equipment, vehicles, and other machinery used in countless industries including construction, transportation, agriculture, rail, marine, mining, and all kinds of factories. DE exposure is often used as a measure of traffic-related air pollution. Several million workers are sometimes or long-term DE exposure. Such occupational exposure to DEPs can also be very high [10]. The association between exposure to air pollutants, especially PM, and morbidity and mortality from cardiovascular and respiratory disease has been well established [11]. It is believed that such environmental toxicities are caused by oxidative stress and inflammatory processes [12]. Increased oxidative stress and inflammation following prenatal exposure to DEPs have also been demonstrated [13].

\section{Neurotoxicity and air pollution exposure: experimental evidence and epidemiological}

In recent years, evidence has been gathered from animal studies and humans epidemiological, suggesting that air 
pollution may adversely affect the central nervous system and contribute to CNS disease [14-16]. PM2.5 and UFPM are of great concern because they can enter the bloodstream and spread to various organs, including the brain [3], In addition to direct access to the brain through the nasal olfactory mucosa $[5,13,17]$. Decreased cognitive function, olfactory dysfunction, hearing impairment, and auditory deficits, depressive symptoms, and other neuropsychiatric side effects in humans have been reported [18,19]. Also, acute exposure to DEPs has been shown to induce EEG changes [20]. Animal studies confirm human observations [1]. For example, dogs exposed to heavy air pollution provided evidence of neuroinflammation and neurodegeneration in different regions of the brain $[12,14,21]$, And animals exposed to the air pollution in the highway tunnel had higher levels of inflammatory cytokines in different regions of the brain [22]. DE exposure causes altered motor activity, memory and learning, the ability to detect new objects and affective behavior, and to produce oxidative stress and neuronal accumulation in the CNS [23-25]. Besides, in our laboratory, we performed a series of studies in mice showing that chronic exposure to DEPs (350-400 $\mu \mathrm{g} / \mathrm{m}^{3}$ for $6 \mathrm{~h}$ ) induces oxidative stress, activation microglia, neuroinflammation and neurogenesis in different regions of the brain such as OB and HI [5].

\section{DEPs exposure and neurotoxicity in mice}

The DEPs consist of PM2.5 or smaller, with an aerodynamic mean diameter of $100 \mathrm{~nm}$. In our previous studies, adult mice (age: 7-8 weeks) were exposed for $6 \mathrm{~h} / \mathrm{d}$ to $350-400 \mu \mathrm{g} / \mathrm{m}^{3}$ DEPs, and afterward investigated neurotoxic effects of DEPs exposure in adult mice [5]. At the end of exposure to DEPs, oxidative stress in brain areas was assessed by measuring lipid peroxidation, and some of the pro-inflammatory cytokines in (IL-1a, IL-1b, IL-6, TNF- $\alpha$ ) was measured. Exposure to DEPs caused significantly increased lipid peroxidation and proinflammatory cytokines in the $\mathrm{OB}$ and the HI [5], while the antiapoptotic cytokine IL-9 decreased [26]. As described, mice exposed to DEPs had significantly higher levels of inflammatory cytokine and lipid peroxidation than control mice [5]. Various factors including sex, age, and genetic history can be modulated the susceptibility to airborne neurotoxicity $[1,27]$. Gender differences are a variable that deserves further research [28] because the information is so limited. Gender differences in sensitivity to traffic-induced neurotoxicity may exist, and this may be due to differential expression of the antioxidant/anti-paraoxonase 2 (PON2) enzyme in the brains of males and females [29,30]. PON2 is an intracellular enzyme, capable of modifying reactive oxygen species and thus protecting cells against stress-induced oxidative toxicity, in addition to having anesthetic and non-inhibitory properties [30]. PON2 levels are inversely correlated with the degree of in vitro susceptibility to neurotoxicity causing oxidative stress. Studies show that in all brain regions and cell types surveyed, PON2 levels are higher in females than in males [31]. There are also gender differences concerning susceptibility to lipid peroxidation induced by $\mathrm{DE}$ and neurodegeneration in vivo $[1,29]$. Acute exposure to DEPs increased malondialdehyde (MDA) levels in the hippocampus 2.8-fold in males and only 1.9 -fold in female mice. Also, the level of TNF-a in the hippocampus was increased 7-fold in males and 2.4-fold in females [32]. In all animals was observed a significant decrease in neurogenesis, which was more evident in female mice. Because air pollution may play a role in the etiology of neurodegenerative and neurodevelopmental diseases such as Parkinson's disease and autism, the prevalence of which is higher in males [33], such gender differences in sensitivity need to be further substantiated. Considering the general relationship of gene interactions with the environment in toxicology and risk assessment the likelihood that genetic polymorphisms may affect neurotoxic sensitivity due to air pollutant exposure should also be considered [34]. To test this hypothesis, one study used Gclm mice, which lack the modified subunit of glutamate-cysteine ligase, the first enzyme, and rate-limiting glutathione (GSH) synthase, a key player in cell defense against oxidative stress. Survey results showed that $\mathrm{Gclm}^{-1-}$ mice have very low levels of GSH in all tissues including the brain [26], although they may regulate other antioxidant pathways. In contrast, $\mathrm{Gclm}^{+/-}$mice have only a modest decrease in GSH but may closely resemble a human Gclm polymorphism [35]. Gclm ${ }^{-1-}$ mice are induced by neuroinflammation (levels of the pro-inflammatory cytokine IL-1b) and oxidative stress (lipid peroxidation) compared to wild-type $\left(\mathrm{Gclm}^{+/+}\right)$mice induced by acute DEPs exposure [36]. Since several genetic polymorphisms of the enzymes are involved in oxidative stress and neural contamination, the possibility of genetic contamination based on neural contamination is warranted by future research.

\section{Exposure to air pollution is a risk factor for neurological diseases}

Animal studies and epidemiological surveys suggest that young people may be particularly vulnerable to the neurotoxicity of exposure to air pollution $[37,38]$. Studies in Mexico City have shown that In addition to the cognitive deficits, high levels of inflammation markers in the brains of children exposed to air pollution [39-41]. Hyperactivity in 7-year-old children is associated with early-life exposure to air pollution [42]. Exposure to air pollutants during pregnancy, in six European groups, was associated with delayed psychomotor development [37]. Some studies have shown that exposure to urban air pollution is inversely associated with sustained attention in adolescents [43], and to reduce cognitive development in preschool children [44]. Surveys' results show that DE exposure may cause neurotoxicity [45]. Maternal DEPs exposure (high levels, $1.0 \mathrm{mg} / \mathrm{m}^{3}$ ) causes changes in locomotor activity, impulsive behavior, and motor coordination in male mice offspring [46]. Behavioral alteration (enhanced bias toward immediate rewards), impulsivity-like behavior, and also long-term impairment of short-term memory, was reported following early postnatal exposure of concentrated ambient PM 
in mice $[47,48]$. Depression-like responses in mice were caused following prenatal exposure to urban air nanoparticles $[13,49]$. Experimental surveys have shown that long-term exposure to DEPs in mice causes changes in motor activity, spatial memory and learning, and the ability to detect new objects, resulting in oxidative damage, neurodegeneration, and alterations in gene expression $[23,50]$.

Autism is a type of neurodevelopmental disorder determined by a significant decrease in social and communication skills and the presence of stereotyped behaviors and the term autism spectrum disorders (ASD) is commonly utilized. Much attention has been paid to autism among the neurological disorders that may be associated with exposure to air pollutants, and some of the recent findings have found associations between exposure to urban air pollutants and autism [51]. The incidence of ASD appears to have increased over the past few decades, and is now estimated to be around $7-9 / 1000$ [52,53]; ASD is also 4 to 12 times more common in males than females [33]. Symptoms of ASD usually present before the age of three and are often accompanied by abnormalities of attention, learning, cognitive function, and sensory processing [51]. Findings indicate that children with ASD have higher levels of oxidative stress [54,55], Also higher neuro-inflammation, microglia activation, and increased systemic inflammation [56,57].

Studies showed that residential proximity to freeways and prenatal and early-life exposure to urban air pollution was associated with autism [58,59]. Another epidemiological study had also similar results [60] and the other study showed that maternal exposure to DE was significantly associated with ASD, especially in boys [61]. Another study also showed an association between ASD and PM exposure, especially when exposure to PM occurred in the third trimester of pregnancy [62]. Also, a cohort study evidenced the higher susceptibility following exposure in the third trimester [63]. The results of some animal research are in agreement with human studies [1]. Reported that postnatal exposure to a high level of ambient air pollutants in male mice causes persistent various neurochemical changes, glial cell activation, and ventriculomegaly [64]. While has been shown that prenatal DEPs exposure, disrupt DNA methylation in the brain, especially affecting genes involved in neurogenesis and neuronal differentiation in mice [65]. Prenatal exposure to DEPs at urban air pollution relevant concentrations (350-400 $\mu \mathrm{g} / \mathrm{m}^{3}$ ) causes a behavioral alteration in adult male mice [13]. Human studies showed that when exposure occurs in the third trimester of pregnancy, the association between ASD and PM exposure is stronger $[62,63]$, which in rats or mice, is equivalent to the first few postnatal weeks [66].

Many epidemiological studies that identify the effects of air pollutants exposure on behavior alteration, especially cognitive behavior, have shown significant effects also in the elderly. So, in addition to the susceptibility of the developing brain, the aging brain may also be especially sensitive to the neurotoxicity caused by exposure to air pollution $[12,27,67,68]$. As mentioned, the primary mechanisms of the harmful effects of air pollution exposure on the CNS appear to be related to neuro-inflammation and oxidative stress $[14,69,70]$. Air pollution is a CNS inflammatory prophylactic stimulus that has been largely overlooked as a risk factor for neurodegenerative diseases [71,72]. Diseases that are likely to be affected by air pollution exposure, including Parkinson's disease (PD) and Alzheimer's disease (AD), are also widespread $[12,73] . P D$ is a devastating motor disorder and the second most common neurological disorder affecting $23-1 \%$ of the population over 50 years. Given these statistics, there is considerable concern that recent findings link air pollutant exposure to neurodegenerative and neuropathological conditions associated with PD and AD. In striking similarity, both $\mathrm{AD}$ and $\mathrm{PD}$ share primary pathology in $\mathrm{OB}$, nuclei, and related pathways, with olfactory deficiency being one of the first findings in both diseases $[12,74]$. This work established the first link between exposure to pollution and accelerating the pathology of neurological disease. These findings have recently been confirmed and extended in humans and other animal models. Also, animal studies have shown that exposure to air pollution induces cytokine production $[75,76]$, increased MAP kinase signaling [76], neurochemical changes [77], lipid peroxidation [75], and behavioral changes [27,78] Taken together, these studies show that air pollutants have CNS effects. Abnormal filamentous protein aggregates and neuritis are the common denominators of PD and AD $[12,79]$. While there are no studies yet to find a direct effect of air pollution on defined levy bodies (a pathological feature of PD) or betaamyloid plaques (Ab) (a pathological feature of $\mathrm{AD}$ ), exposure to urban air pollution causes neurological inflammation [12,39].

Therefore, humans and young animals may be particularly vulnerable to the inflammatory effects of exposure to air pollution, and these effects may accumulate throughout one's lifetime. Whereas ischemic stroke [80], multiple sclerosis (exposure to secondhand smoke increases risk) [81], and PD (airborne manganese content is associated with increased risk) [82]. Currently, only CNS diseases are epidemiologically based. However, given the high prevalence of PD and AD, the association between neurodegeneration and the pathogenesis of $\mathrm{PD} / \mathrm{AD}$, CNS pathology induced by air pollution, and the high prevalence of exposure to air pollution, the expansion of mechanical studies and Follow the epidemiological. The dangers of other CNS diseases are of concern to human health. As said, our studies in the behavioral alteration effects of exposure to DEPs in mice will be continues.

\section{Conclusions and suggest further studies}

Some recent studies suggest that the CNS may be an important target for exposure to air pollutants, and in particular nanoparticles in urban air, of which DEPs are a common source. 
As mentioned earlier, there is a strong convergence between human epidemiological studies and experimental animal studies on the final biochemical and behavioral considerations that are affected by exposure to air pollution [1]. Exposure to air pollutants is problematic given the suggested link between air pollution exposure and neurological diseases such as ASD or dementia. Also, given that short-term exposure can cause biochemical changes associated with such diseases, exposure to air pollution in the workplace is usually low but can be very worrying. In general, further studies are needed to better describe the effects of air pollutant exposure on the CNS, its underlying mechanisms, and its role in the cause of neurological and neurodevelopmental diseases. In particular, due to the higher prevalence of developmental neurological disorders (such as ASD) and neurological disorders (such as PD) in men, gender may be affected by air pollution [28]. Given the complex nature of these common ambient toxins, CNS pathology is likely due to the synergistic interaction of multiple pathways and mechanisms, creating air pollutants in an environmentally relevant and important challenge. While epidemiology querying is associated with an increased risk of stroke, MS, and PD exposure to certain types of air pollution, further epidemiological and mechanical studies of the association between air pollution components and CNS disease are of particular importance to human health.

\section{Declaration of interest}

Funding: This review received no external funding and was initiated and funded by Dr. Ehsanifar Research Lab, Tehran, Iran.

\section{Acknowledgment}

We thank Dr. Ehsanifar Lab. Tehran, Iran.

\section{References}

1. Costa LG, Cole TB, Coburn J, Chang YC, Dao K, et al. Neurotoxicants are in the air: convergence of human, animal, and in vitro studies on the effects of air pollution on the brain. Biomed Res Int. 2014; 2014. PubMed: https://pubmed.ncbi.nlm.nih.gov/24524086/

2. Van Donkelaar A, Martin RV, Brauer M, Boys BL. Use of satellite observations for long-term exposure assessment of global concentrations of fine particulate matter. Environ Health Perspect. 2015; 123: 135-143.

PubMed: https://pubmed.ncbi.nlm.nih.gov/25343779/

3. Genc S, Zadeoglulari Z, Fuss SH, Genc K. The adverse effects of air pollution on the nervous system. J Toxicol. 2012; 2012: 782462. PubMed: https://pubmed.ncbi.nlm.nih.gov/22523490/

4. Peters A, Veronesi B, Calderón-Garcidueñas L, Gehr P, Chen LC, et al. Translocation and potential neurological effects of fine and ultrafine particles a critical update. Part Fibre Toxicol. 2006: 3: 13. PubMed: https://pubmed.ncbi.nlm.nih.gov/16961926/

5. Ehsanifar M, Tameh AA, Farzadkia M, Kalantari RR, Zavareh MS, et al Exposure to nanoscale diesel exhaust particles: Oxidative stress, neuroinflammation, anxiety and depression on adult male mice. Ecotoxicol Environ Saf. 2019; 168: 338-347.

PubMed: https://pubmed.ncbi.nlm.nih.gov/30391838/

6. Jafari AJ, Ehsanifar M, Arfaeinia H. The Share of Different Vehicles in Air Pollutant Emission in Tehran, Using 2013 Traffic Information. Caspian J Health Res. 2016; 2: 28-36.
7. Ghio AJ, Smith CB, Madden MC. Diesel exhaust particles and airway inflammation. Curr Opin Pulm Med. 2012; 18: 144-150. PubMed: https://pubmed.ncbi.nlm.nih.gov/22234273/

8. Ris C. US EPA health assessment for diesel engine exhaust: a review. Inhal Toxicol. 2007; 19(sup1): 229-239.

PubMed: https://pubmed.ncbi.nlm.nih.gov/17886071/

9. EPA U. Health assessment document for diesel engine exhaust. Washington, DC, 600/8-90/057F, 2002.

10. Pronk A, Coble J, Stewart PA. Occupational exposure to diesel engine exhaust: a literature review. J Expo Sci Environ Epidemiol. 2009; 19 : 443-457

PubMed: https://pubmed.ncbi.nlm.nih.gov/19277070/

11. Rao X, et al. Effect of particulate matter air pollution on cardiovascular oxidative stress pathways. Antioxid Redox Signal. 2018; 28: 797-818. PubMed: https://pubmed.ncbi.nlm.nih.gov/29084451/

12. Ehsanifar M, Banihashemian S, Ehsanifar M. Exposure to Air Pollution Nanoparticles: Oxidative Stress and Neuroinfl ammation. J Biomed Res Environ Sci. 2021; 2: 964-976.

13. Ehsanifar M, Jafari AJ, Nikzad H, Zavareh MS, Atlasi MA, et al. Prenatal exposure to diesel exhaust particles causes anxiety, spatial memory disorders with alters expression of hippocampal pro-inflammatory cytokines and NMDA receptor subunits in adult male mice offspring Ecotoxicol Environ Saf. 2019; 176: 34-41.

PubMed: https://pubmed.ncbi.nlm.nih.gov/30921694/

14. Ehsanifar M. Exposure To urban air pollution nanoparticles and CNS disease. On J Neur Br Disord. 2021; 5: 520-526.

15. Block ML, Calderón-Garcidueñas L. Air pollution: mechanisms of neuroinflammationandCNSdisease. TrendsNeurosci.2009;32:506-516. PubMed: https://pubmed.ncbi.nlm.nih.gov/19716187/

16. Block ML, Elder A, Auten RL, Bilbo SD, Chen $\mathrm{H}$, et al. The outdoor air pollution and brain health workshop. Neurotoxicology. 2012; 33: 972-984. PubMed: https://pubmed.ncbi.nlm.nih.gov/22981845/

17. Garcia GJ, Schroeter JD, Kimbell JS. Olfactory deposition of inhaled nanoparticles in humans. Inhal Toxicol. 2015; 27: 394-403. PubMed: https://pubmed.ncbi.nlm.nih.gov/26194036/

18. Guxens M, Sunyer J. A review of epidemiological studies on neuropsychological effects of air pollution. Swiss Med Wkly. 2012; 141; w13322.

PubMed: https://pubmed.ncbi.nlm.nih.gov/22252905/

19. Fonken LK, Xu X, Weil ZM, Chen G, Sun Q, et al. Air pollution impairs cognition, provokes depressive-like behaviors and alters hippocampal cytokine expression and morphology. Mol Psychiatry. 2011; 16:987-995. PubMed: https://pubmed.ncbi.nlm.nih.gov/21727897/

20. Crüts $B$, van Etten L, Törnqvist $H$, Blomberg $A$, Sandström $T$, et al Exposure to diesel exhaust induces changes in EEG in human volunteers. Part Fibre Toxicol. 2008. 5: 4.

PubMed: https://pubmed.ncbi.nlm.nih.gov/18334019/

21. Calderon-Garciduenas L, Maronpot RR, Torres-Jardon R, HenríquezRoldán $\mathrm{C}$, Schoonhoven $\mathrm{R}$, et al. DNA damage in nasal and brain tissues of canines exposed to air pollutants is associated with evidence of chronic brain inflammation and neurodegeneration. Toxicol Pathol. 2003. 31: 524-538.

PubMed: https://pubmed.ncbi.nlm.nih.gov/14692621/

22. Bos I, De Boever P, Emmerechts J, Buekers J, Vanoirbeek J, et al. Changed gene expression in brains of mice exposed to traffic in a highway tunnel. Inhal Toxicol. 2012; 24: 676-686.

PubMed: https://pubmed.ncbi.nlm.nih.gov/22906174/

23. EhsanifarM, JafariAJ,MontazeriZ,KalantariRR, GholamiM, etal.Learning and memory disorders related to hippocampal inflammation following exposure to air pollution. J Environ Health Sci Eng. 2021; 19: 261-272. PubMed: https://pubmed.ncbi.nlm.nih.gov/34150234/ 
24. Win-Shwe TT, Fujimaki H. Nanoparticles and neurotoxicity. Int J Mo Sci. 2011; 12: 6267-6280.

PubMed: https://pubmed.ncbi.nlm.nih.gov/22016657/

25. Levesque S, Taetzsch T, Lull ME, Kodavanti U, Stadler K, et al. Diese exhaust activates and primes microglia: air pollution, neuroinflammation, and regulation of dopaminergic neurotoxicity. Environ Health Perspect. 2011; 119: 1149-1155.

PubMed: https://pubmed.ncbi.nlm.nih.gov/21561831/

26. Giordano G, White CC, McConnachie LA, Fernandez C, Kavanagh TJ, et al. Neurotoxicity of domoic acid in cerebellar granule neurons in a genetic model of glutathione deficiency. Mol Pharmacol. 2006; 70: 2116-2126.

PubMed: https://pubmed.ncbi.nlm.nih.gov/17000861/

27. Ehsanifar M. Anxiety and Depression Following Diesel Exhaust NanoParticles Exposure in Male and Female Mice. J Neurophysiol Neuro Disord. 2020; 8: 1-8.

28. Clougherty JE. A growing role for gender analysis in air pollution epidemiology. Environ Health Perspect. 2010; 118: 167-176.

PubMed: https://pubmed.ncbi.nlm.nih.gov/20123621/

29. Giordano G, Tait L, Furlong CE, Cole TB, Kavanagh TJ, et al. Gender differences in brain susceptibility to oxidative stress are mediated by levels of paraoxonase-2 expression. Free Radic Biol Med. 2013; 58: 98-108.

PubMed: https://pubmed.ncbi.nlm.nih.gov/23376469/

30. Costa LG, de Laat R, Dao K, Pellacani C, Cole TB, et al Paraoxonase-2 (PON2) in brain and its potential role in neuroprotection. Neurotoxicology. 2014; 43: 3-9.

PubMed: https://pubmed.ncbi.nlm.nih.gov/24012887/

31. Giordano G. Higher susceptibility of male mice to diesel exhaust neurotoxicity. Toxicologist. 2013; 132: 54.

32. Koutseff A, Mittelhaeuser C, Essabri K, Auwerx J, Meziane H. Impact of the apolipoprotein $\mathrm{E}$ polymorphism, age and sex on neurogenesis in mice: Pathophysiological relevance for Alzheimer's disease? Brain Res. 2014; 1542: 32-40.

PubMed: https://pubmed.ncbi.nlm.nih.gov/24140109/

33. Schaafsma SM, Pfaff DW. Etiologies underlying sex differences in autism spectrum disorders. Front Neuroendocrinol. 2014; 35: 255-271. PubMed: https://pubmed.ncbi.nlm.nih.gov/24705124/

34. Costa LG, Eaton DL. Gene-Environment Interactions: Fundamentals of Ecogenetics. 2005: Wiley Online Library.

35. Nakamura SI. Polymorphism in the 5'-flanking region of human glutamate-cysteine ligase modifier subunit gene is associated with myocardial infarction. Circulation. 2002; 105: 2968-2973.

36. Weldy CS, White CC, Wilkerson HW, Larson TV, Stewart JA, et al. Heterozygosity in the glutathione synthesis gene $\mathrm{Gclm}$ increases sensitivity to diesel exhaust particulate induced lung inflammation in mice. Inhal Toxicol. 2011; 23: 724-735

PubMed: https://www.ncbi.nlm.nih.gov/pmc/articles/PMC3337699/

37. Guxens M, Garcia-Esteban R, Giorgis-Allemand L, Forns J, Badaloni C et al. Air pollution during pregnancy and childhood cognitive and psychomotor development: six European birth cohorts. Epidemiology. 2014; 636-647.

PubMed: https://pubmed.ncbi.nlm.nih.gov/25036432/

38. Calderón-Garcidueñas $L$, Kavanaugh $M$, Block M, D'Angiulli A Delgado-Chávez $\mathrm{R}$, et al. Neuroinflammation, hyperphosphorylated tau, diffuse amyloid plaques, and down-regulation of the cellular prion protein in air pollution exposed children and young adults. J Alzheimer's Dis. 2012; 28: 93-107.

PubMed: https://pubmed.ncbi.nlm.nih.gov/21955814/

39. Calderón-GarcidueñasL, SoltAC, Henríquez-RoldánC,Torres-JardónR, Nuse $B$, et al. Long-term air pollution exposure is associated with neuroinflammation, an altered innate immune response, disruption of the blood-brain barrier, ultrafine particulate deposition, and accumulation of amyloid $\beta-42$ and $\alpha$-synuclein in children and young adults. Toxicol Pathol. 2008; 36: 289-310.

PubMed: https://pubmed.ncbi.nlm.nih.gov/18349428/

40. Calderón-Garcidueñas L, Engle R, Mora-Tiscareño A, Styner M, Gómez-Garza G, et al. Exposure to severe urban air pollution influences cognitive outcomes, brain volume and systemic inflammation in clinically healthy children. Brain Cogn. 2011; 77: 345-355 PubMed: https://pubmed.ncbi.nlm.nih.gov/22032805/

41. Calderon-Garciduenas L, Cross JV, Franco-Lira M, Aragón-Flores M, Kavanaugh $\mathrm{M}$, et al. Brain immune interactions and air pollution: macrophage inhibitory factor (MIF), prion cellular protein (PrPC), Interleukin-6 (IL-6), interleukin 1 receptor antagonist (IL-1Ra), and interleukin-2 (IL-2) in cerebrospinal fluid and MIF in serum differentiate urban children exposed to severe vs. low air pollution. Fronti Neurosci. 2013; 7: 183.

PubMed: https://pubmed.ncbi.nlm.nih.gov/24133408/

42. Newman NC, Ryan P, Lemasters G, Levin L, Bernstein D, et al. Trafficrelated air pollution exposure in the first year of life and behavioral scores at 7 years of age. Environ Health Perspect. 2013; 121: 731-736. PubMed: https://pubmed.ncbi.nlm.nih.gov/23694812/

43. Kicinski M, Vermeir G, Van Larebeke N, Hond ED, Schoeters G, et al. Neurobehavioral performance in adolescents is inversely associated with traffic exposure. Environ Int. 2015; 75: 136-143. PubMed: https://pubmed.ncbi.nlm.nih.gov/25461422/

44. Sunyer J, Esnaola M, Alvarez-Pedrerol M, Forns J, Rivas I, et al. Association between traffic-related air pollution in schools and cognitive development in primary school children: a prospective cohort study. PLoS Med. 2015; 12: e1001792.

PubMed: https://pubmed.ncbi.nlm.nih.gov/25734425/

45. Ema M, Naya M, Horimoto M, Kato H. Developmental toxicity of diesel exhaust: a review of studies in experimental animals. Reprod Toxicol. 2013. 42: 1-17.

PubMed: https://pubmed.ncbi.nlm.nih.gov/23831197/

46. Suzuki T, Oshio S, Iwata M, Saburi H, Odagiri $T$, et al. In utero exposure to a low concentration of diesel exhaust affects spontaneous locomotor activity and monoaminergic system in male mice. Part Fibre Toxicol. 2010; $7: 7$.

PubMed: https://pubmed.ncbi.nlm.nih.gov/20331848/

47. Allen JL, Conrad K, Oberdörster G, Johnston CL, Sleezer B, et al. Developmental exposure to concentrated ambient particles and preference for immediate reward in mice. Environ Health Perspect. 2013; 121: 32-38

PubMed: https://pubmed.ncbi.nlm.nih.gov/23063827/

48. Allen JL, Liu X, Weston D, Prince L, Oberdörster G, et al. Developmenta exposure to concentrated ambient ultrafine particulate matter air pollution in mice results in persistent and sex-dependent behaviora neurotoxicity and glial activation. Toxicol Sci. 2014; 140: 160-178. PubMed: https://pubmed.ncbi.nlm.nih.gov/24690596/

49. Davis DA, Bortolato M, Godar SC, Sander TK, Iwata N, et al. Prenata exposure to urban air nanoparticles in mice causes altered neuronal differentiation and depression-like responses. PloS One. 2013; 8 : e64128.

PubMed: https://pubmed.ncbi.nlm.nih.gov/23734187/

50. Win-Shwe TT, Fujitani Y, Kyi-Tha-Thu C, Furuyama A, Michikawa T, et al. Effects of diesel engine exhaust origin secondary organic aerosols on novel object recognition ability and maternal behavior in BALB/c mice. Int J Environ Res Public Health. 2014; 11: 11286-11307. PubMed: https://pubmed.ncbi.nlm.nih.gov/25361045/

51. Levy S, DS M, Schultz RT. Autism. Lancet. 2009; 374: 1627-1638. PubMed: https://pubmed.ncbi.nlm.nih.gov/19819542/

52. Boyle CA, Boulet S, Schieve LA, Cohen RA, Blumberg SJ, et al. Trends in the prevalence of developmental disabilities in US children, 1997-2008. Pediatrics. 2011; 127: 1034-1042.

PubMed: https://pubmed.ncbi.nlm.nih.gov/21606152/ 
53. Control CFD. Prevention, Autism and Developmental Disabilities Monitoring Network Surveillance Year 2008 Principal Investigators: Prevalence of autism spectrum disorders-Autism and Developmental Disabilities Monitoring Network, 14 sites, United States, 2008. MMWR Surveill Summ. 2012; 61: 1-19.

PubMed: https://pubmed.ncbi.nlm.nih.gov/22456193/

54. Rose S, Melnyk S, Pavliv O, Bai S, Nick TG, et al. Evidence of oxidative damage and inflammation associated with low glutathione redox status in the autism brain. Transl Psychiatry. 2012; 2: e134-e134.

PubMed: https://pubmed.ncbi.nlm.nih.gov/22781167/

55. Frustaci A, Neri M, Cesario A, Adams JB, Domenici E, et al. Oxidative stress-related biomarkers in autism: systematic review and metaanalyses. Free Radic Biol Med. 2012; 52: 2128-2141.

PubMed: https://pubmed.ncbi.nlm.nih.gov/22542447/

56. Suzuki K, Sugihara G, Ouchi Y, Nakamura K, Futatsubashi M, et al Microglial activation in young adults with autism spectrum disorder. JAMA Psychiatry. 2013; 70: 49-58.

PubMed: https://pubmed.ncbi.nlm.nih.gov/23404112/

57. Depino AM. Peripheral and central inflammation in autism spectrum disorders. Mole Cellu Neurosci. 2013; 53: 69-76.

PubMed: https://pubmed.ncbi.nlm.nih.gov/23069728/

58. Volk HE, Hertz-Picciotto I, Delwiche L, Lurmann F, McConnell R. Residential proximity to freeways and autism in the CHARGE study. Environ Health Perspect. 2011; 119: 873-877.

PubMed: https://pubmed.ncbi.nlm.nih.gov/21156395/

59. Volk HE, Lurmann F, Penfold B, Hertz-Picciotto I, McConnell R. Trafficrelated air pollution, particulate matter, and autism. JAMA Psychiatry. 2013; 70: 71-77.

PubMed: https://pubmed.ncbi.nlm.nih.gov/23404082/

60. Becerra TA, Wilhelm M, Olsen J, Cockburn M, Ritz B. Ambient air pollution and autism in Los Angeles county, California. Environ Health Perspect. 2013. 121: 380-386.

PubMed: https://pubmed.ncbi.nlm.nih.gov/23249813/

61. Roberts AL, Lyall K, Hart JE, Laden F, Just AC, et al. Perinatal air pollutant exposures and autism spectrum disorder in the children of Nurses' Health Study II participants. Environ Health Perspect. 2013; 121: 978-984.

PubMed: https://pubmed.ncbi.nlm.nih.gov/23816781/

62. KalkbrennerAE, WindhamGC,SerreML,AkitaY,WangX, etal.Particulate matter exposure, prenatal and postnatal windows of susceptibility, and autism spectrum disorders. Epidemiology. 2015; 26: 30-42. PubMed: https://pubmed.ncbi.nlm.nih.gov/25286049/

63. Roberts AL, Lyall K, Hart JE, Just AC, et al. Autism spectrum disorder and particulate matter air pollution before, during, and after pregnancy: a nested case-control analysis within the Nurses' Health Study II cohort. Environ Health Perspect. 2015; 123: 264-270.

PubMed: https://pubmed.ncbi.nlm.nih.gov/25522338/

64. Allen JL, Liu X, Pelkowski S, Palmer B, Conrad K, et al. Early postnatal exposure to ultrafine particulate matter air pollution: persistent ventriculomegaly, neurochemical disruption, and glial activation preferentially in male mice. Environ Health Perspect. 2014; 122: 939-945. PubMed: https://pubmed.ncbi.nlm.nih.gov/24901756/

65. Tachibana K, Takayanagi K, Akimoto A, Ueda K, Shinkai Y, et al Prenatal diesel exhaust exposure disrupts the DNA methylation profile in the brain of mouse offspring. J Toxicol Sci. 2015; 40: 1-11.

PubMed: https://pubmed.ncbi.nlm.nih.gov/25560391/

66. Bayer SA, Altman J, Russo RJ, Zhang X. Timetables of neurogenesis in the human brain based on experimentally determined patterns in the rat. Neurotoxicology. 1993; 14: 83-144.

PubMed: https://pubmed.ncbi.nlm.nih.gov/8361683/

67. Ehsanifar M. Does Exposure to Air Pollution Fine Particles and COVID-19 Contribute to the Risk of Ischemic Stroke? Health. 2021; 2: 1020.
68. Ehsanifar M, Montazeri Z, Taheri MA, Rafati M, Behjati M, et al. Hippocampal inflammation and oxidative stress following exposure to Diesel exhaust nanoparticles in male and female mice. Neurochem Int. 2021; 104989.

PubMed: https://pubmed.ncbi.nIm.nih.gov/33582162/

69. Qian L, Flood PM, Hong JS. Neuroinflammation is a key player in Parkinson's disease and a prime target for therapy. J Neural Transm. 2010; 117: 971-979.

PubMed: https://pubmed.ncbi.nIm.nih.gov/20571837/

70. Lee YJ, Han SB, Nam SY, Oh KW, Hong JT. Inflammation and Alzheimer's disease. Arch Pharm Res. 2010; 33: 1539-1556. PubMed: https://pubmed.ncbi.nIm.nih.gov/21052932/

71. Seagrave J, McDonald JD, Bedrick E, Edgerton ES, Gigliotti AP, et al. Lung toxicity of ambient particulate matter from southeastern US sites with different contributing sources: relationships between composition and effects. Environ Health Perspect. 2006; 114: 1387-1393.

PubMed: https://pubmed.ncbi.nlm.nih.gov/16966093/

72. Ehsanifar M, Banihashemian S, Farokhmanesh F. Exposure to Ambient Ultra-Fine Particles and Stroke. 2021.

73. Hirtz D, Thurman DJ, Gwinn-Hardy K, Mohamed M, Chaudhuri AR, et al. How common are the "common" neurologic disorders? Neurology. 2007; 68: 326-337.

PubMed: https://pubmed.ncbi.nlm.nih.gov/17261678/

74. Doty RL. The olfactory vector hypothesis of neurodegenerative disease: is it viable? Ann Neurol. 2008; 63: 7-15.

PubMed: https://pubmed.ncbi.nlm.nih.gov/18232016/

75. Campbell A, Oldham M, Becaria A, Bondy SC, Meacher D, et al Particulate matter in polluted air may increase biomarkers of inflammation in mouse brain. Neurotoxicology. 2005; 26: 133-140. PubMed: https://pubmed.ncbi.nlm.nih.gov/15527881/

76. Kleinman M, Araujo JA, Nel A, Sioutas C, Campbell A, et al. Inhaled ultrafine particulate matter affects CNS inflammatory processes and may act via MAP kinase signaling pathways. Toxicol Lett. 2008; 178: 127-130.

PubMed: https://pubmed.ncbi.nlm.nih.gov/18420360/

77. Sirivelu MP, Mohan Kumar SMJ, Wagner JG, Harkema JR, Mohan Kumar PS. Activation of the stress axis and neurochemical alterations in specific brain areas by concentrated ambient particle exposure with concomitant allergic airway disease. Environ Health Perspect. 2006; 114: 870-874

PubMed: https://pubmed.ncbi.nlm.nih.gov/16759987/

78. Zanchi AC, Venturini CD, Saiki M, Saldiva PHN, Barros HMT, et al. Chronic nasal instillation of residual-oil fly ash (ROFA) induces brain lipid peroxidation and behavioral changes in rats. Inhal Toxicol. 2008; 20: 795-800.

PubMed: https://pubmed.ncbi.nlm.nih.gov/18645718/

79. Block ML, Zecca L, Hong JS. Microglia-mediated neurotoxicity: uncovering the molecularmechanisms. NatRev Neurosci. 2007;8:57-59. PubMed: https://pubmed.ncbi.nlm.nih.gov/17180163/

80. Lokken RP, Wellenius GA, Coull BA, Burger MR, Schlaug G, et al Air pollution and risk of stroke: underestimation of effect due to misclassification of time of event onset. Epidemiology. 2009;20: 137-142. PubMed: https://pubmed.ncbi.nlm.nih.gov/19244659/

81. Mikaeloff Y, Caridade G, Tardieu M, Suissa S, KIDSEP Study Group. Parental smoking at home and the risk of childhood-onset multiple sclerosis in children. Brain, 2007; 130: 2589-2595. PubMed: https://pubmed.ncbi.nlm.nih.gov/17827175/

82. Finkelstein MM, Jerrett M. A study of the relationships between Parkinson's disease and markers of traffic-derived and environmental manganese air pollution in two Canadian cities. Environ Res. 2007; 104: 420-432.

PubMed: https://pubmed.ncbi.nlm.nih.gov/17445792/ 